\title{
Promoting Pedestrian Eco-Mobility Trouough the Characteristics of the Physical Environment of Algerian Urban Context? The Example of Algiers/What Degree of Influence?
}

\author{
Madiha Khelfat ${ }^{1}$, Tahar Baouni ${ }^{2}$
}

\begin{abstract}
In the context of sustainable urban development, the promotion of alternative means of transport is essential. Assuming that in the Algerian context, that pedestrian mobility is discouraged by the state of the urban space. We want to discover how to encourage pedestrian eco-mobility, how this mobility is influenced by the physical characteristics of the urban environment. For this, we investigate the resident population in several neighbourhoods of the Algerian capital via a survey to establish the link between mobility behaviour, opinions and socio-economic characteristics. This work tries to put under the light through the case of the Algerian cities, the means to promote and manage the pedestrian mobility by the register of the visual sensory of the urban frame. This work tries to have as an implication the promotion of the pedestrian sustainable mobility to improve the health of the inhabitants, to develop the urbanity of our cities and to moderate the use of motorized transport means strongly polluting for the environment and economically viable.
\end{abstract}

Keywords: Alternative mobility; pedestrian mobility; pedestrian; route; physical urban setting; perception; Algiers; Algeria

\section{Introduction}

Different fields of research have pointed out the benefits of walking, which is now a particular focus for the promotion of health, environment and urbanity. The challenge of mobility at the beginning of the 21 st century would therefore be to activate the potential of walking, as the 20th century was able to activate the full potential of the automobile by giving the walker the means to access the multiple resources of the city, to benefit from the richest experiences, to play obstacles.

\section{Theory Focus}

The landscape is subjective (perceived) and it can be measured from a relatively rational point of view. We can even speak of "emotional rationality" to explain human action with regard to the sensible qualities of spaces and the emotions and affects they generate. (Audas \& Martouzet, 2008, Piombini, 2013).

Several fields of study: public health, social science, transportation engineering, urban planning and architecture, the quality of the built environment and walkability. Figure 1 shows the relationship between the physical characteristics of the environment and the

| 'Ph.D., Laboratoire Ville, Urbanisme et Développement Durable, Ecole Polytechnique d'Architecture et d'Urbanisme, Alger

| 2 Prof., Laboratoire Ville, Urbanisme et Développement Durable, Ecole Polytechnique d'Architecture et d'Urbanisme, Alger 
walking behaviour.

Walkability is defined as the degree of ease with which one can do everything on foot and close to home.

Pedestrian empowerment is another concept that has emerged in favor of the promotion of soft mobility and the sharing of the way for pedestrians to benefit from an urban environment that can be walked on, with material and symbolic arrangements for urban walking.

\section{Pedestrian Mobility in Algerian Context}

According to the 2004 household and displacement survey, there is a decrease in walking mobility accompanied by an increase in household motorization.

Table 1 shows that unaccompanied motives account for only 29.43\% of total travel, showing that people generally travel by obligation.

Table 1: Travel by reason required and not obliged - Household survey and displacement, 2004

\begin{tabular}{|c|c|c|}
\hline Motif & Nombre de déplacements & $\%$ \\
\hline Motifs Obligés & 3357580 & 70.57 \\
\hline Motifs non obligés & 1400259 & 29.43 \\
\hline T O T A L & $\mathbf{4 7 5 7 8 3 9}$ & $\mathbf{1 0 0}$ \\
\hline
\end{tabular}

The household and displacement survey of 2004 is the last and the second carried out in the Algiers agglomeration after that carried out by BETUR in 1990. The results of this survey constitute the main source of information available on the movements urban. The survey involved a random sample of 5088 households representing $01.06 \%$ of the total resident households in the Algiers agglomeration (made up of 57 communes).

The survey results show that motorized travel has increased over decades, while walking has decreased and continues to decline (see Figure 2).

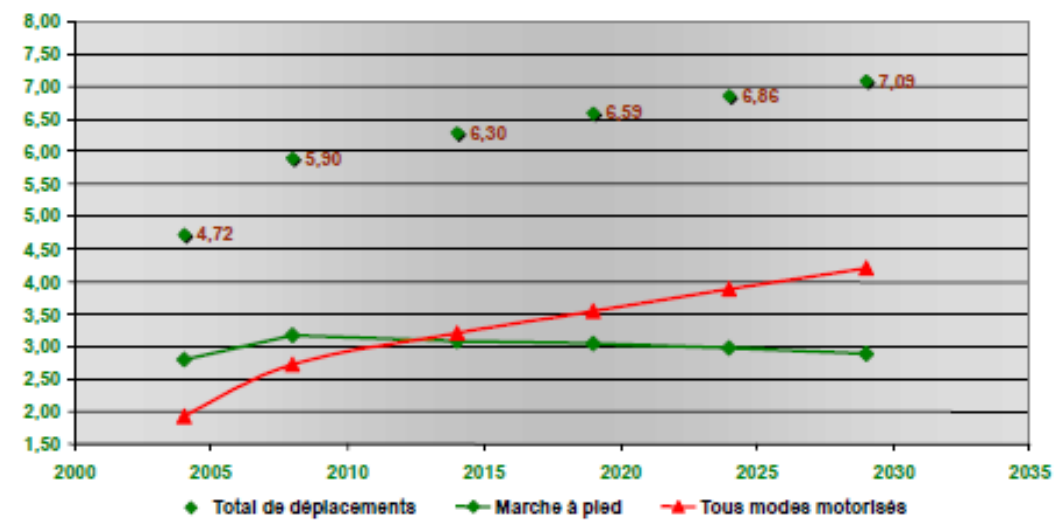

Figure 2 : Daily mobility projection - Household survey and displacement database, 2004 


\section{Travel and Mobility by Gender and Mode}

Men move more than women do. This difference is even more pronounced if we look only at trips in motorized modes (Household and Travel Survey, 2004). This also confirms, as we have already pointed out, that workstations are much more occupied by the male population than the female population. In contrast, women make as many trips on foot as men. This observation must be qualified by the fact that, in a household equipped with a single car, it is most often the man who disposes of it that the woman (Household survey and displacement, 2004).

Travel and mobility of persons by sex and age groupAlmost identical mobility between the two sexes until the age of 20; a widening gap in mobility between the sexes at age 21; A gradual decline in mobility among the elderly; more than 50 years for men and from the forties for women (Household and displacement survey, 2004), or even the figure 3.

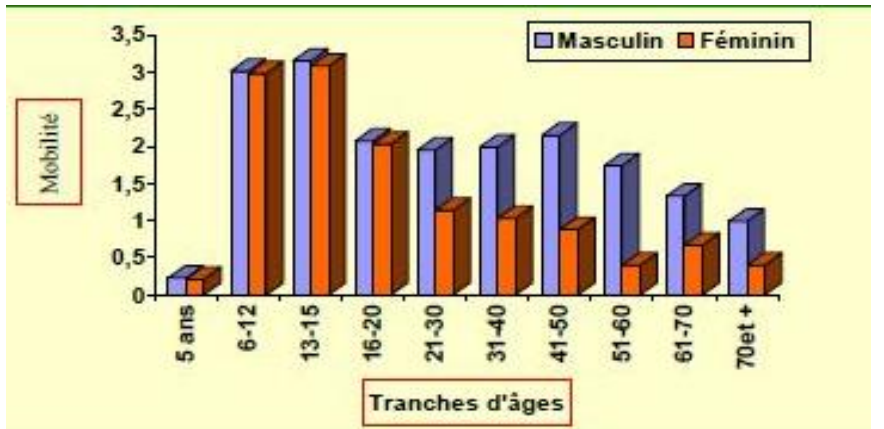

Figure 3: Mobility of persons by sex and age group, - Household survey and displacement database, 2004

\section{Distribution of Movements over Time}

The figure below shows that travel and traffic increases during peak hours: from 6 am to 9 am $(27.52 \%$ of the daily traffic for motorized modes), which explains the high level of congestion of roads ; from $11 \mathrm{am}$ to $2 \mathrm{pm}$ (37.68\% of daily walking traffic), which corresponds to meal times (lunch) and 16 to 18 hours (20.86\% of daily TMM traffic) time to leave the (Household survey and displacement, 2004).

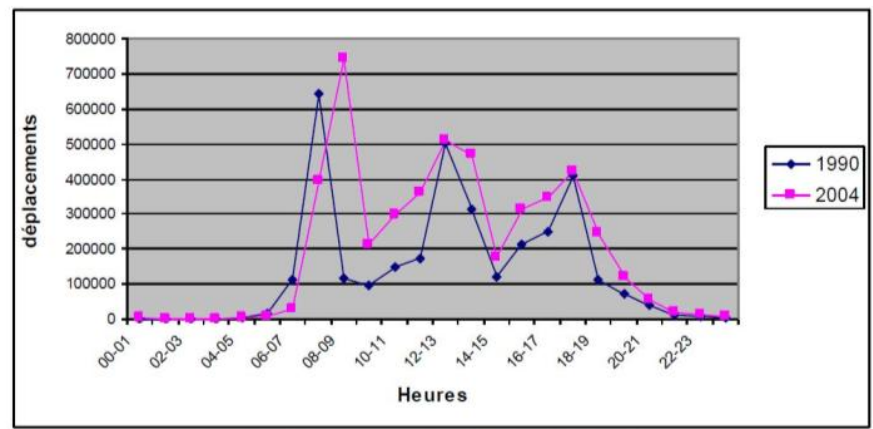

Figure 4: Evolution of trips by time zone - Safar zitoun and Tabti- talamali, 2009 


\section{Displacements According to the Reasons}

From the figure below, we note that the MAP is important for home study.

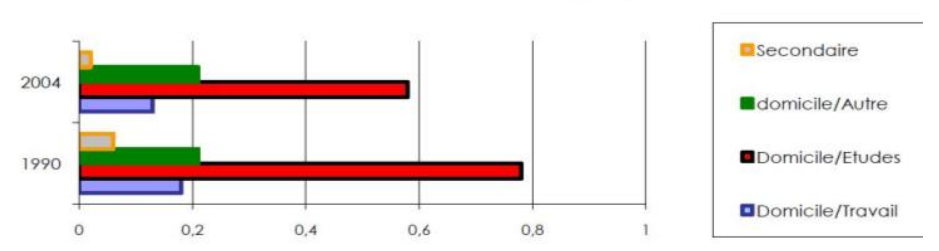

Figure 5: Evolution of mobility while walking - Safar zitoun and Tabti-talamali, 2009

\section{Travel by Public Transport}

Public transport is an important element in promoting soft mobility. Since the 2004 household and travel survey, $71.72 \%$ of respondents admit that they are ready to switch from private car use if there is an improvement in public transportation.

\section{Influence of the Physical Characteristics of the Urban Environment to the Mobility in the Algerian Context}

Assuming that pedestrian mobility in the Algerian context is discouraged by the state of the urban space: Absence of sidewalks, disrepair of their condition, insecurity and discomfort ... etc. (Figure 6 and 7).

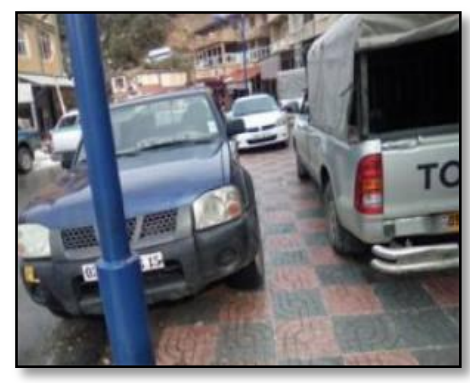

Figure 6: Image of sidewalks in a municipality of Algiers - Authorger

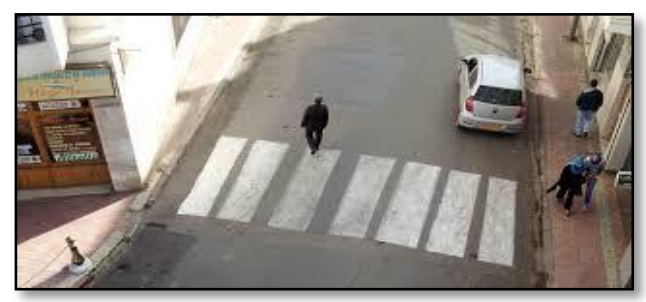

Figure 7: Surface to be trampled down- author 
For this, we investigate the resident population in several neighborhoods of the Algerian capital via a survey entretien to establish the link between mobility behavior, opinions and socio-economic characteristics.

\section{Méthod}

To establish the link between mobility behavior, opinions and socio-economic characteristics, an interview was conducted on the pedestrian mobility with 10 living people in the city of Algiers, and this during the month of May of the year 2018. Three women and seven men were surveyed; the respondents are between 19 and 65 years.

\section{Résults}

The results of the interview are as follows:

\subsection{Recreational Travel}

For the reason of recreation, two out of ten people say that they go out on average several times a month while three of them go out only once.

\subsection{Traveling to school}

Half of the respondents accompany their children to school. Their movements are halfway on foot. The reasons given by those who prefer to accompany their children by a motorized means of transport are distance, lack of time and comfort of the movement.

\subsection{Movements of less than $2 \mathrm{Km}$}

For a trip of less than $2 \mathrm{~km}$ (equivalent to $30 \mathrm{~min}$ walking time), all respondents generally use MAP. A person uses the bus or the private car second.

\subsection{Opinions about MAP}

All respondents believe that walking is beneficial for health and for the preservation of the environment.

7 out of 10 say that health benefits affect their choices to walk while 8 say street conditions discourage them.

\subsection{The MAP for the Reason of Transportation and Recreation}

9 out of 10 people think that walking is more or less advantageous for recreation trips while for transportation trips; half of people think that walking is not beneficial. The nuisances for the MAP:

All the people surveyed admit that they will like to walk more. What discourages is: "Lack of time, health reason";

"Less sidewalks, sidewalks not spacious and defective";

"Lack of time, social interaction";

"Lack of time, nuisances";

"I do it when it's possible"; 
"Lack of time, pedestrian space reduced compared to the number of the population";

"Lack of spaces for pedestrians".

In addition, all respondents believe that pollution is harmful to pedestrians.

Factors that encourage walking:

According to the respondents, we can encourage walking by:

"Clean tracks, attractive shops, wide roads, street furniture, minimize the car";

"Being in a group, the person is more motivated to walk more";

"By improving the condition of sidewalks, creating green spaces, paying more attention to street hygiene, creating spaces especially for walking»; «Improve the state of the streets, create green spaces, create spaces only for women Restrict working time";

"Creation of meeting areas for friends, security for walking at night";

"Reduce the use of vehicles in certain circuits, ensure more pedestrian lanes; guarantee the quality of its tracks: safe, convenient, and pleasant ";

"Green spaces, pedestrian roads".

\subsection{Factors that Affect Walking Movements}

According to the respondents, the following factors encourage walking for recreation: comfort of movement, speed of travel, proximity to public transport, distance from travel, direct co-presence with others and safety.

The discouraging factors are the distance of the displacements and the direct co-presence with the others. (Figure 9).

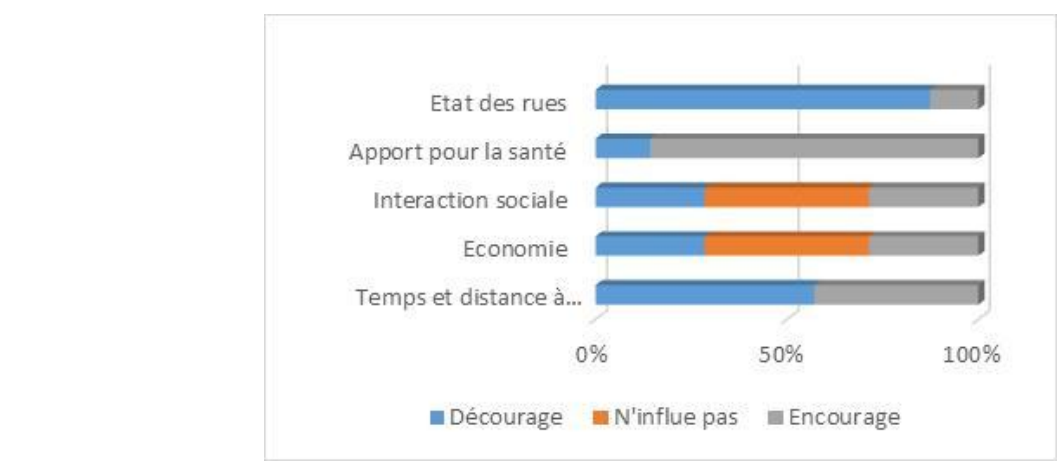

Figure 9: Factors influencing the choice of MAP travel- auteur

In addition, the factors that encourage the choice to walk for utilitarian reasons (work, shopping and others) are comfort of movement, speed of movement, proximity to public transport and safety. While the distance of displacements is a discouraging factor.

\subsection{Climatic Factors and Walking Movements}

Seven respondents say that winter climatic factors affect walking while only three say it does not. For utility travel, the presence of puddles on the sidewalks is considered a discouraging factor.

All respondents admit that the mild sun encourages walking while the stifling sun, the winds and the rains are discouraging factors. 


\subsection{Factors Influencing Travel by Public Transport}

Several interviewees admit that the number of standing passengers and incivilities discourage the use of public transport. See the figure below.

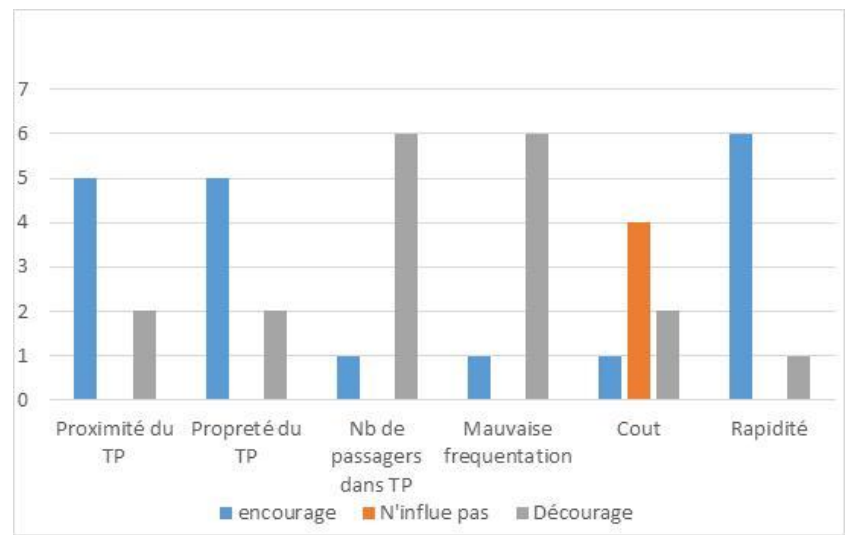

Figure 10 : Factors influencing travel by public transport-auteur

According to respondents, the cleanliness of public transport is more or less missing; the number of passengers in public transport is present and hinders travel by public transport. Figure 11 shows people's views on public transit since the 2004 household and displacement survey.

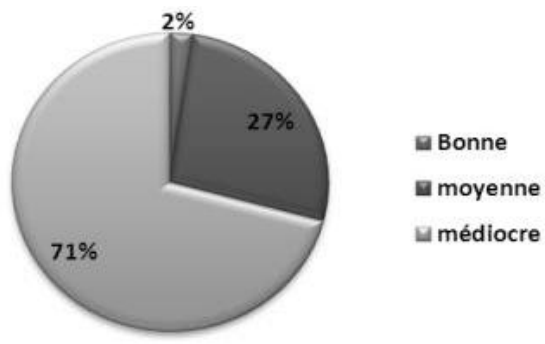

Figure 11 : Quality of the public transport service - Safar zitoun et Tabti-talamali, 2009

\subsection{Indispensability of the Private Car for Travel}

As shown in Figure 12, the opinions differ on the indispensability of the particular car for travel.

Figure 12 : Indispensability of the private car for travel-author 
The same characteristics, we find them in other Algerian cities, from the analysis of the household survey of the town of Setif, it shows a large predominance of walking (69\%) to the detriment of the bus and the private vehicle (Rahmani, 2012).

The reasons for displacement show that the most common reasons for walking are education (Rahmani, 2012). Similar characteristics with that of the 2004 household survey.

In addition, the analysis of the perceived landscape components of downtown Setif showed that the choice of the pedestrian route in the town center of Setif is determined by the urban opportunities available to him, and that the choice of individuals is by preference or by need (Rahmani, 2012).

\section{Instruments of Composition of the Urban in Algeria}

\subsection{Land Use Plan}

In contrast to the P.D.A.U., which is a master plan, the P.O.S. is a detailed plan; these guidelines on the urban form consist in the determination of: the height of the constructions and rules of prospect, the density that is done by coefficient of footprint and coefficient of occupation on the ground.

It dictates the urban form by directives of hygiene, public lighting; the use of public transport, more sustainable modes of transport, improve the management of traffic flows in the city, manage parking as an instrument for controlling the modal split, the hierarchy of exchange poles, implementation easements constructions and open spaces and plantations, non-aedificandi areas; alignment / road; external appearance. Buildings must have a unity of appearance and homogeneity of building materials used (PDAU of Algiers, 2017).

The regulation also specifies the nature of public works and facilities and the nature and destination of authorized and prohibited constructions. The location of buildings in relation to public roads and rights-of-way relative to one another (Khelfat, 2016).

\subsection{Charter of Public Spaces (CEP)}

Massive use of the private car leads to a heavy occupation of urban space by means of transport, which causes obvious conflicts and disadvantages for pedestrians and their circulation. In recognition of this, a charter of public spaces was added recently in the 2017 PDAU of the wilaya of Algiers. This document emphasizes the importance of public space for the city in its various dimensions through the adoption of the principles of development of soft mobility networks, the pedestrian valuation of historic areas, through the qualification pedestrian spaces, the qualification of the structuring pedestrian network, giving it better conditions of comfort, especially on the most congested or problematic paths; the improvement of pedestrian safety, in particular through the correction of urban design and accident-prone situations; the diffusion of the benefits of soft modes and the organization of awareness-raising campaigns, directed, among others, towards the school population and the facilitation of the legibility of the public transport offer by users (PDAU of Algiers, 2017) .

The guidelines can be summarized as 12 key points: character of the place I Identity, continuity | Permeability; quality, readability; adaptability | flexibility; diversity; 
ergonomics | comfort, security; sustainability and inclusion | Social Cohesion (Algiers PDAU, 2017).

\section{Conclusion}

From this analysis, it can be said that in the context of Algiers and Algeria in general, MAP is a mode of displacement influenced by the external physical environment and that to improve this mode of displacement, it is necessary to improve the physical environment. Urban and the quality of public transport offered.

It can be said that the charter of public spaces is a means that will soon influence the quality of urban public space given the quality of the directives offered.

\section{References}

Baouni,T., Bakour, M et Berchache, R. (2013). «Effets de la multi-modalité à Alger sur la mobilité des usagers », Insaniyat / إنسانيات, 62 | 2013. URL : http://journals.openedition.org/insaniyat/14298 ; DOI : $10.4000 /$ insaniyat.14298

BETUR., Groupement EMA/BETUR-CENEAP (1990). Household Surveys on Travel in the Agglomeration of Algiers, 2004.

Ewing, R., \& Handy, S. (2009). Measuring the unmeasurable: Urban design qualities related to walkability. Journal of Urban Design, 14(1), 65-84

Khelfat, M. (2016). Ambiances visuelles et morphologie urbaine. Master's thesis in architecture and urban environment, University of Jijel.

Piombini, A. (2006). Modélisation des choix d'itinéraires pédestres en milieu urbain. Approche géographique et paysagère. Phd Thesis in geography. University of Franche-Comté.

Rahmani, A. (2012). La perception sensorielle dans les espaces urbains, mouvement et choix d'itinéraires pedestres dans les espaces urbais de Setif Cas du centre-ville de Sétif. Master's thesis, University Mohamed Khider - Biskra

Safar zitoun, M., Tabti-talamali, A. (2009). La mobilité urbaine dans l'agglomération d'Alger : évolutions et perspectives étude de cas. Rapport définitif, ALGIERS.

Wilaya d'Alger. (2017). Master Plan of Planning and Urban Planning. 